\title{
VISÕES DE CONTEXTUALIZAÇÃO DE PROFESSORES DE QUÍMICA NA ELABORAÇÃO DE SEUS PRÓPRIOS MATERIAIS DIDÁTICOS
}

\author{
Erivanildo Lopes da Silva* \\ Maria Eunice Ribeiro Marcondes**
}

RESUMO: Este trabalho procurou investigar, numa ação de formação continuada, os entendimentos a respeito da contextualização no ensino de Química de um grupo de professores antes, durante e após discussões e reflexões de outros enfoques de contextualização, e como estas se refletiriam no planejamento de seus materiais instrucionais. A investigação foi realizada por meio de questionários abertos, atividades, relatos gravados em vídeo, análise de documentos e entrevistas semi-estruturadas. Para análise, foram elaboradas quatro perspectivas de contextualização. Os resultados mostraram ampliação das concepções dos professores, que caracterizavam, inicialmente, a contextualização como simples exemplificação e descrição de fatos e passaram a compreender ideias mais elaboradas como a abordagem de questões sociais. Contudo os dados mostraram que a maioria das unidades didáticas elaboradas não refletia elementos da ampliação dessas ideias.

Palavras-chave: Contextualização. Ensino de Química. Formação Continuada de Professores.

\section{VISIONS OF CONTEXTUALIZATION OF CHEMISTRY TEACHERS IN THE ELABORATION OF THEIR OWN DIDACTIC MATERIALS}

ABSTRACT: This work aimed to investigate, during an action of educational development, the understanding of a group of teachers of the Chemistry teaching contextualization before, during and after discussions and reflections of different points of view of contextualization, and how they were reproduced in the planning of instructional materials. The investigation was developed by using opened questions, activities, videotaped teachers' reports, analysis of documents and structured interviews. Four perspectives on the contextualization of teaching were prepared for the research. The results showed a broadening of the teachers'conceptions, initially characterized as simple exemplifications and description of facts but later developing into well elaborated ideas of contextualization as the approach of social issues. However, the results pointed out that most of the elaborated didactic units did not reflect elements of these ideas broadening.

Keywords: Contextualization. Chemistry Teaching. Teacher's Further Education. 


\section{INTRODUÇÃO}

A contextualização no ensino de ciências vem sendo defendida por orientações oficiais, educadores e pesquisadores como um princípio norteador de uma educação voltada para a cidadania que possibilite a aprendizagem significativa de conhecimentos científicos e a intervenção consciente.

No âmbito da disciplina Química, essas orientações se manifestam, por exemplo, nas sugestões dos Parâmetros Curriculares Nacionais para Ensino Médio - PCNEM - quando sugerem (BRASIL, 1999) a utilização das vivências dos alunos e os fatos do dia-a-dia, da tradição cultural para construir conhecimentos químicos que permitam refazer leituras do mundo. Os PCN+ (BRASIL, 2002) enfatizam que conteúdos e temas devem favorecer a compreensão do mundo natural, social, político e econômico.

Parte das ideias de contextualização apresentadas nos documentos oficiais retrata tendências atuais da área do ensino de Ciências. Entre elas, destacam-se os estudos do cotidiano, caracterizado pela exploração de situações corriqueiras ligadas ao dia-a-dia das pessoas nas situações de ensino (LUTFI, 1992), também a da contextualização na perspectiva do movimento CTS, Ciência Tecnologia e Sociedade (ACEVEDO DIAZ, 1996; AIKENHEAD, 1994), e mais recentemente, segundo alguns pesquisadores brasileiros, a aproximação destas com a pedagogia de Paulo Freire (AULER, 2007).

No que tange aos professores de química do ensino médio, verificamse discursos favoráveis às ideias apregoadas pelos documentos oficiais sem que isto signifique, entretanto, a adoção de práticas de ensino condizentes com tais discurssos, seja pela pouca compreensão, ou por apontarem empecilhos para sua realização.

Neste contexto, procurou-se investigar os entendimentos a respeito da contextualização no ensino de Química de um grupo de professores antes, durante e após discussões e reflexões de outros enfoques de contextualização, e como estas se refletiriam no planejamento de seus materiais instrucionais.

O levantamento dos dados foi realizado por meio de questionários abertos, atividades, relatos gravados de professores, análise de documentos e entrevistas semi-estruturadas, recursos da pesquisa qualitativa que possibilitaram desvelar dados sobre as concepções dos professores e como eles se apropriaram das ideias discutidas numa ação de formação continuada (FC) pautada na elaboração de materiais didáticos próprios.

\section{CONTEXTUALIZAC̣ÃO NO ENSINO DE CIÊNCIAS}

Lutfi (1992) aponta diferentes interpretações atribuídas ao cotidiano, ou seja, à contextualização, que vão desde a simples resposta a uma curiosidade do aluno e a exemplificação, à elaboração de projetos de ensino que informam 
sobre a ciência, a tecnologia e suas aplicações (sociedade), até a perspectiva de conhecer para poder transformar a realidade.

Santos e Mortimer (1999), estudando as concepções de um grupo de professores a respeito da contextualização no ensino de química, identificaram três diferentes entendimentos: a contextualização como estratégia para facilitar a aprendizagem; como descrição científica de fatos e processos do cotidiano do aluno e como desenvolvimento de atitudes e valores para a formação de um cidadão crítico. Os autores apontaram que grande parte dos professores pesquisados entende a contextualização como uma descrição científica de fatos e processos do cotidiano do aluno.

Pode-se perceber o reflexo dessas concepções em boa parte dos livros didáticos que os professores adotam. Neste sentido, Wartha (2002) estudou como esses livros, em uso na época, incorporaram a ideia de contextualização apresentada nos PCNEM. O autor aponta que nos livros, a contextualização se restringe à exemplificação de fatos do dia-a-dia e à descrição científica de fatos e processos do cotidiano do aluno, ou seja, similar as concepções dos professores estudados por Santos e Mortimer e bem diferentes das orientações presentes nos PCNEM.

A contextualização no ensino tem sido foco de vários debates, desde as concepções filosóficas, a sua epistemologia, até a própria palavra contextualização. Segundo Machado (2004, p. 146), a palavra correta a ser considerada seria contextuação. "Apesar do uso frequente da palavra contextualização, segundo o dicionário de Caldas Aulete, entre outros, o ato de se referir ao contexto é expresso pelo verbo contextuar, de onde deriva a palavra contextuação". Embora o termo contextuação pareça ser mais adequado, neste trabalho será adotado para a discussão o termo contextualização, uma vez que este é frequentemente utilizado em documentos oficiais e pesquisas acadêmicas.

Atualmente, o termo cotidiano, quando relacionado à contextualização, tem se caracterizado por ser um estudo de situações ligadas ao dia-a-dia das pessoas com intuito de estabelecer algum vínculo com conhecimentos científicos, com vista à aprendizagem de conceitos (DELIZOICOV et al., 2002).

Chassot (2001) ressalta que o ensino nessa perspectiva virou uma espécie de modismo que traz embutido o propósito de ensinar pura e simplesmente os conceitos científicos. Geralmente, tais situações são introdutórias aos conteúdos teóricos e têm o objetivo de chamar a atenção do aluno, aguçar sua curiosidade, porém exclusivamente motivacional, com único propósito de ensinar conteúdos (CAJAS, 2001; LUTFI, 1992).

A contextualização no ensino também está relacionada ao movimento Ciência, Tecnologia e Sociedade (CTS). Esse movimento surgiu como uma proposta de caráter inovador, com a perspectiva de compreender melhor a ciência e a tecnologia no seu contexto social (ACEVEDO DIAZ, 1996). Trouxe, em sua concepção, rompimento com a visão neutra e salvacionista da ciência, assim como a ideia de que a tecnologia determina os caminhos da ciência e 
sociedade, o determinismo tecnológico (AULER, 2003).

No campo educacional, o movimento apresenta alguns modelos metodológicos para esse estudo, podendo destacar o sugerido por Aikenhead (1994).

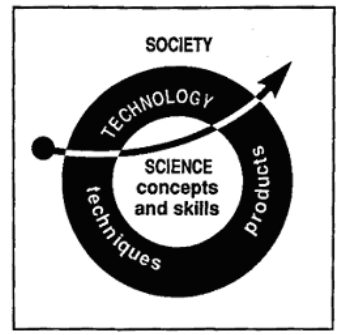

Figura 1 - Modelo de abordagem CTS de Aikenhead

De acordo com este modelo, como mostra a figura 1, a situação de estudo deve partir de questões sociais (Society) relacionadas a conhecimentos tecnológicos (Technology, techniques e products) e científicos (Science, concepts and skills). Dessa forma, o conhecimento científico é definido em função do tema e da tecnologia. Depois de compreendidos os conhecimentos científicos, retorna-se à tecnologia. Ao final, conforme apresenta o modelo, retoma-se à questão social. Esse estudo sistemático, segundo o autor, permite a tomada de decisão sobre a questão social.

As orientações do movimento CTS, segundo pesquisadores como Auler (2001, 2003) e Santos (2002), apresentam similaridades com as da pedagogia de Paulo Freire (2002). Entre as semelhanças destaca-se o ensino baseado em temas geradores partindo do estudo do meio social e político do aluno.

Auler et al. (2007) ressaltam, entretanto, que os temas geradores da pedagogia freiriana são extraídos da prática de vida dos alunos para serem problematizados e isso não é uma característica marcante na perspectiva de ensino CTS. Para o autor, o ensino de ciências, nesta perspectiva, deve conhecer o aluno enquanto indivíduo inserido num contexto social, de onde deverão emergir os conhecimentos a serem problematizados, isso por meio da pesquisa realizada com, entre, e por eles. Para Auler, essa situação não é percebida no movimento CTS, pois os temas geradores, segundo essa perpsectiva de ensino, embora relacionados ao meio social do aluno, são apresentados geralmente pelo próprio professor.

Outros autores apontam mais similaridades e distinções entre as perspectivas de ensino CTS e transformadora da realidade social. Teixeira (2003) aponta que as questões sociais devem ser estudadas com vistas a compreendêlas e transformá-las, aspecto que para o autor, não é contemplado no movimento CTS, pois geralmente, o ensino nessa perspectiva se restringe ao estudo de questões relativas aos impactos sociais provocados pela ciência e tecnologia. 
Contudo, o autor afirma que as duas perspectivas apresentam mais compatibilidades do que divergências.

$\mathrm{Na}$ interface das duas perspectivas de ensino contextualizado destacam-se os momentos pedagógicos propostos por Delizoicov e Angotti (1991). Estes autores propuseram um modelo de ensino de Ciências baseado na codificação-problematização-decodificação de Freire, constituído de três momentos pedagógicos: problematização, organização (do conhecimento) e aplicação do conhecimento.

$\mathrm{Na}$ problematização deve-se apresentar aos alunos situações reais, conhecidas e vivenciadas por eles, envolvidas nos temas. A meta é problematizar o conhecimento que os alunos expõem. O professor deve fomentar a discussão das respostas dos alunos e explorar explicações contraditórias mostrando limitações no conhecimento característico do senso comum dos alunos.

O segundo momento pedagógico é a organização do conhecimento, etapa em que os conhecimentos selecionados devem ser necessários para a compreensão dos temas e da problematização inicial, portanto, deve ter um caráter interdisciplinar para possibilitar responder às perguntas que foram construídas na problematização.

O terceiro momento pedagógico destina-se a abordar sistematicamente o conhecimento que vem sendo incorporado pelo aluno, para que possa analisar e interpretar a situação inicial e ainda aplicá-lo em outras situações problemáticas. É fundamental que o aluno possa perceber esta aplicação e apoderar-se desse conhecimento, utilizando-o para ter um novo olhar sobre o problema inicial e solucionar outro problema relacionado aos mesmos conhecimentos científicos.

No nosso entender, a contextualização no ensino de Ciências que privilegia o estudo de contextos sociais com aspectos políticos, econômicos e ambientais, fundamentado em conhecimentos das ciências e tecnologia, é fundamental para desenvolver um ensino que venha a contribuir para a formação de um aluno crítico, atuante e sempre que possível transformador de sua realidade desfavorável.

Para se realizar um ensino dito contextualizado é necessário discuti-lo nos âmbitos das formações inicial e continuada de professores, de modo a problematizar e sistematizar os conhecimentos teóricos pertinentes ao ensino contextualizado.

Pimenta et al. (2004) apontam que a parceria colaborativa entre pesquisadores e docentes, na formação continuada de professores, pode contribuir para um estudo profícuo da prática pedagógica em bases teóricas. Para os autores, este entendimento de formação e pesquisa não compreende o professor como um mero receptor de ensinamentos dos pesquisadores/ formadores e sim como um participante de um grupo colaborativo que detém conhecimentos a serem considerados nos momentos de reflexões.

Outra perspectiva para a formação continuada de professores, capaz de criar condições propícias para introduzir com eficácia as inovações desejadas, 
é a construção e reconstrução de materiais didáticos (MAZZEU, 1998). Tenreiro-Vieira e Vieira (2006), no âmbito CTS, defendem a construção e validação de materiais didáticos nas ações junto a professores no ensino de Ciências.

\section{METODOLOGIA}

A pesquisa foi realizada por meio de um curso, oferecido pela Diretoria de Ensino Regional ${ }^{1}$, situada na grande São Paulo. Foram realizados seis encontros ao longo de 2005, com participação efetiva de 17 professores. Para o desenvolvimento do curso optou-se por adotar o modelo metodológico dos momentos pedagógicos de Delizoicov e Angotti (1991).

Desta forma, o primeiro momento foi a problematização das possíveis concepções atribuídas à contextualização no ensino de Química. Foi pedido aos professores que relatassem seus entendimentos e formulassem questionamentos a respeito do ensino dito contextualizado. Procurou-se investigar os entendimentos dos professores por meio de questionários abertos e de seus discursos, gravados em vídeo.

O segundo momento se deu por meio de discussões e reflexões compartilhadas (PIMENTA, 2002), sobre os conhecimentos teóricos, estimulando os professores a tecer relações entre tais referenciais e as suas práticas. Essas discussões visavam fornecer respostas às questões levantadas na problematização do tema. Os professores foram convidados a analisar e discutir propostas temáticas de ensino elaboradas e aplicadas por outros (PROJETO PRÓ-CIÊNCIA², 2003), sobre as formas de contextualização que os materiais didáticos traziam em sua estrutura, procurando identificar entendimentos e objetivos educativos sobre a temática em questão. Esses materiais didáticos apresentavam as características da contextualização como: exemplificação e curiosidades; descrição científica de fatos e processos; fundamentos CTS e transformação social.

Para coleta de dados, nessa etapa, adotou-se um questionário aberto em que se procurava verificar as relações que os professores estabeleciam entre materiais didáticos produzidos por outros professores e as concepções de contextualização apresentadas ao longo do curso.

O terceiro momento aconteceu na construção dos materiais instrucionais dos professores participantes da pesquisa, ou seja, eles iniciaram a elaboração de suas próprias propostas de ensino, tendo em vista vencer a barreira da exemplificação e descrição de fatos. Para orientar a elaboração das unidades dos professores foi apresentado a eles um modelo estrutural de unidade didática contextualizada (SÃO PAULO, 2007, p.21). A figura 2 apresenta a visualização desse modelo. 


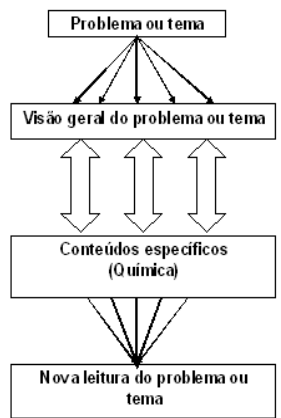

Figura 2 - Estrutura conceitual para elaboração de unidades

A estrutura do modelo de unidade, similar ao modelo de Aikenhead (1994), parte de um tema gerador (problematizado ou não). Na segunda parte estrutural, visão geral do problema ou do tema, apresenta conhecimentos CTS. Em seguida, explora os conhecimentos específicos, isto é, os conceitos da química pertinentes à discussão do tema. Por fim, espera-se que a unidade apresente uma nova leitura do tema. Esta etapa deve possibilitar uma compreensão embasada em conhecimentos científicos, sociais e tecnológicos trabalhados.

Assim, após a construção de seus respectivos materiais didáticos, procurou-se investigar o modo que os professores trabalharam as ideias discutidas no curso em suas unidades didáticas. Foram escolhidos seis professores para as entrevistas com base nas ideias manifestadas nas suas respectivas unidades didáticas, porém os resultados dessas entrevistas não serão discutidos nesse trabalho.

\subsection{Análise dos dados}

Verificaram algumas tendências a partir dos referenciais teóricos e análise prévia dos dados que contribuíram para a construção das categorias de análise dos dados da pesquisa, tanto as concepções dos professores quanto das suas unidades didáticas. Assim, foram construídas quatro categorias de contextualização:

Aplicação do conbecimento químico (AC) - contextualização como apresentação de ilustrações e exemplos de fatos do cotidiano ou aspectos tecnológicos relacionados ao conteúdo químico que está sendo tratado.

Descrição cientifica de fatos e processos (DC) - os conhecimentos químicos estão postos de modo a fornecer explicações para fatos do cotidiano e de tecnologias, estabelecendo ou não relação com questões sociais. A Temática está em função dos conteúdos (SANTOS; MORTIMER, 1999).

Compreensão da realidade social (CRS) - O conhecimento químico é utilizado como ferramenta para o enfrentamento de situações problemáticas, o conhecimento científico está em função do contexto sócio-técnico (ACEVEDO DIAZ, 1996, 2003; AIKENHEAD, 1994).

Transformação da realidade social (TRS) - discussão de situações problemas de forte teor social, buscando sempre, o posicionamento e intervenção 
social por parte do aluno na realidade social problematizada. Os conteúdos estão em função da problemática em estudo (AULER, 2001, 2003; FREIRE, 2002; LUTFI, 1992; TEIXEIRA, 2003).

Para a análise das unidades didáticas e a relação delas com as categorias de contextualização foi construído um instrumento de análise a partir do modelo de unidade didática.

Tabela 1 - Relação das estruturas do modelo de material instrucional e níveis com as categorias de contextualização

\begin{tabular}{|c|c|c|c|c|}
\hline $\begin{array}{l}\text { Entendimentos de } \\
\text { contextualização }\end{array}$ & $\begin{array}{c}\text { 1- Tema ou situação } \\
\text { problema } \\
\text { [nível] }\end{array}$ & $\begin{array}{l}2 \text { - Enfoque CTSA } \\
\text { na visão geral do } \\
\text { tema ou problema } \\
\text { [nível] }\end{array}$ & $\begin{array}{c}3 \text { - Conhecimentos } \\
\text { específicos da } \\
\text { química em relação } \\
\text { ao tema ou problema } \\
\text { [nível] }\end{array}$ & $\begin{array}{c}4 \text { - Nova visão do } \\
\text { tema ou problema } \\
\text { [nível] }\end{array}$ \\
\hline $\begin{array}{l}\text { Aplicação do } \\
\text { conhecimento }\end{array}$ & $\begin{array}{c}\text { Tema } \\
\text { (1) }\end{array}$ & $\begin{array}{c}C>\mathrm{TS} / \mathrm{A} \\
\text { (tendência à ciência) } \\
\text { (1) }\end{array}$ & $\begin{array}{c}\text { relação fraca } \\
\text { (1) }\end{array}$ & $\begin{array}{c}\text { Não apresenta } \\
\text { (1) }\end{array}$ \\
\hline $\begin{array}{l}\text { Descrição científica } \\
\text { de fatos e processos }\end{array}$ & $\begin{array}{c}\text { Tema } \\
\text { (1) }\end{array}$ & $\begin{array}{c}\text { C > TS/A } \\
\text { (tendência à ciência) } \\
\text { (1) }\end{array}$ & $\begin{array}{l}\text { Relação media } \\
\text { (2) }\end{array}$ & $\begin{array}{c}\text { retoma o tema } \\
\text { (2) }\end{array}$ \\
\hline $\begin{array}{l}\text { Compreensão da } \\
\text { realidade social }\end{array}$ & $\begin{array}{l}\text { Problema } \\
\text { (2) }\end{array}$ & $\begin{array}{c}\text { C=TSA } \\
\text { (tendência à equidade } \\
\text { nas relações CTS) } \\
\text { (3) }\end{array}$ & $\begin{array}{l}\text { relação forte } \\
\text { (3) }\end{array}$ & $\begin{array}{c}\text { apresenta nova } \\
\text { situação que amplia os } \\
\text { entendimentos sobre } 0 \\
\text { problema } \\
\text { (3) }\end{array}$ \\
\hline $\begin{array}{l}\text { Transformação da } \\
\text { realidade social }\end{array}$ & $\begin{array}{c}\text { Problema } \\
\text { (2) }\end{array}$ & $\begin{array}{c}\mathrm{CT}<\mathrm{S} / \mathrm{A} \\
\text { (tendência à sociedade } \\
\text { ou sociedade/ambiente) } \\
\text { (2) }\end{array}$ & $\begin{array}{l}\text { relação forte } \\
\text { (3) }\end{array}$ & $\begin{array}{c}\text { apresenta nova } \\
\text { situação provocativa } \\
\text { com vistas a resolver } 0 \\
\text { problema } \\
\text { (4) }\end{array}$ \\
\hline
\end{tabular}

A tabela 1 apresenta as correlações que o instrumento permite estabelecer entre as categorias de contextualização e seus respectivos níveis de complexidade metodológica com as partes estruturais das unidades dos professores. Então se tem:

Situação problema ou tema - presença de um tema (nível 1) ou ocorrência de uma problematização (nível 2).

$V$ isão geral do problema ou tema - parte do instrumento que permite a análise das informações que explicitam o tema ou problema abordado e as relações com aspectos das áreas CTSA que a unidade possa trazer. Assim, as relações CTS foram classificadas em: C>TS/A (tendência à ciência, nível 1), $\mathrm{CT}<\mathrm{S} / \mathrm{A}$ (tendência à sociedade ou sociedade/ambiente, nível 2) e C=TSA (tendência à equidade nas relações CTS, nível 3).

Conhecimento específico da Química - se o conhecimento da química tratado na unidade do professor estabelece relação forte (nível 3), média (nível 2) ou fraca (nível 1) com o tema ou problema.

Nova leitura do tema ou problema - analisa se a unidade didática retoma alguma discussão sobre o tema ou problema (nível 2) ou não (nível 1), apresenta nova situação que amplia os entendimentos sobre o problema (nível 3), ou ainda, apresenta nova situação provocativa com vistas a resolver o problema (nível 4). 


\section{DISCUSSÃO DOS RESULTADOS}

A análise das concepções iniciais dos professores revelou forte aproximação das ideias de contextualização no ensino de Química apresentadas anteriormente. As respostas dos professores foram classificadas na categoria em que ocorreram mais elementos de aproximação.

A tabela 2 mostra que quatro professores $(23,5 \%)$ demonstraram ideias de contextualização relacionadas a aplicações do conhecimento químico, ou seja, apresentam concepções sobre contextualização como exemplificação e ilustrações de contextos para ensinar o conteúdo de química. Já doze professores $(70,5 \%)$ pareceram entender a contextualização como uma estratégia capaz de permitir a descrição científica de fatos e processos.

Apenas um professor $(6 \%)$ apresentou entendimento da contextualização na perspectiva da compreensão da realidade social. A concepção de contextualização para transformação social não fez parte do discurso de nenhum dos professores cursistas.

Tabela 2 - Entendimentos iniciais dos professores ${ }^{3}$ sobre contextualização

Entendimentos sobre contextualização ao inicio do curso

\begin{tabular}{|c|c|c|c|c|c|}
\hline \multicolumn{2}{|c|}{ Professores } & \multicolumn{4}{|c|}{ Início dos encontros } \\
\hline & & AC & DC & CRS & TRS \\
\hline 1 & PA & & $\mathrm{x}$ & & \\
\hline 2 & PB & & $\mathrm{x}$ & & \\
\hline 3 & PC & & $\mathrm{x}$ & & \\
\hline 4 & PD & & $x$ & & \\
\hline 5 & PE & $x$ & & & \\
\hline 6 & PF & $\mathrm{x}$ & & & \\
\hline 7 & PG & & $x$ & & \\
\hline 8 & PH & & $x$ & & \\
\hline 9 & PI & & $x$ & & \\
\hline 10 & PJ & & $x$ & & \\
\hline 11 & PL & & $\mathrm{x}$ & & \\
\hline 12 & PM & & & $x$ & \\
\hline 13 & PN & & $x$ & & \\
\hline 14 & PO & $x$ & & & \\
\hline 15 & PP & & $x$ & & \\
\hline 16 & PO & & $\mathrm{x}$ & & \\
\hline 17 & PR & $\mathrm{x}$ & & & \\
\hline \multicolumn{2}{|c|}{ TOTAL } & 4 & 12 & 1 & 0 \\
\hline & & $23,5 \%$ & $70,5 \%$ & $6 \%$ & $\mathbf{0 \%}$ \\
\hline
\end{tabular}

Legenda: AC: Aplicação do Conhecimento Químico; DC: Descrição Científica de Fatos e Processos;

CRS: Compreensão da Realidade Social; TRS: Transformação da Realidade Social

Pode-se inferir, a partir dessa análise que, os professores apresentaram forte apego à sequência tradicional de conteúdos químicos em detrimento de temáticas tecnológicas e sociais, ou seja, a contextualização tem um único propósito, que é ensinar conteúdos de química. 
A seguir apresentamos algumas falas dos professores que caracterizam as categorizações AC e DC realizadas:

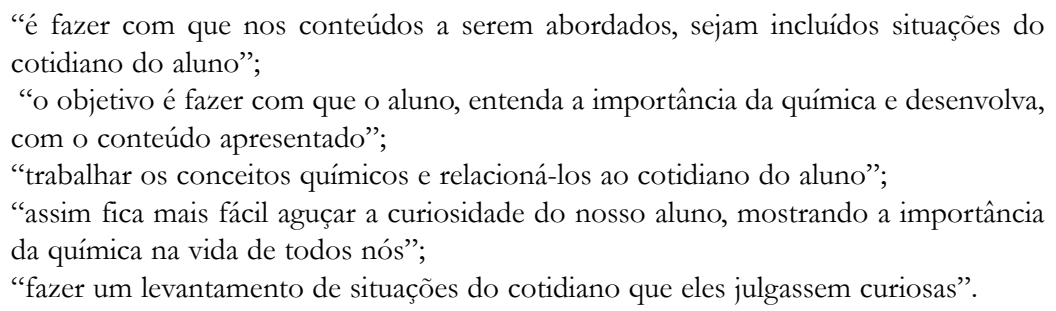

Classificamos o professor PM na categoria CRS por conta dos relatos como:

"utilizar situações do dia-a-dia com problemas relacionados à química (...o que falem sobre ciência e tecnologia com o conteúdo a ser relacionado)";

"resolvi trabalhar assim para conquistar o interesse dos alunos pelas aulas de química e tentar incorporar a importância do estudo da química aos interesses dos alunos"; "procuro partir de exemplos e fenômenos que sejam do conhecimento do aluno e explorá-los para ensinar química";

"jornais e revistas onde discutem alguns problemas ambientais, discutindo como podem nos atingir e como prevenir tais problemas".

Durante o segundo momento pedagógico foi solicitado aos professores que analisassem quatro unidades construídas por outros professores e procurassem relacioná-las às categorias de contextualização. Cada uma das unidades apresentava uma única perspectiva de contextualização, na qual, nove professores (PA, PB, PD, PI, PH, PQ, PJ, PO e PR) compreenderam as ideias de contextualização, pois souberam identificá-las nas quatro unidades analisadas e apresentaram justificativas coerentes com as categorias de contextualização. Por outro lado, os demais professores (PC, PE, PM, PF, PG, PL, PN e PP), pareceram não ter compreendido bem as ideias de contextualização.

Dos 17 professores cursistas, 15 terminaram a elaboração de uma unidade didática, tendo sido produzido um total de nove unidades. Destas, quatro foram construídas individualmente, quatro em duplas - proposta inicial do curso - e uma unidade construída em trio.

Procurou-se sistematizar a estrutura do instrumento (vide tabela 1) na forma de gráfico, como ilustrada na figura 3. No eixo X estão representados por números as estruturas das unidades: (1) Situação problema ou tema, (2) Visão geral do problema ou tema, (3) Conhecimento específico de química (em relação ao tema), (4) Nova leitura do tema ou problema. No eixo Y, os números representam os níveis de complexidade das atividades relacionadas às categorias de contextualização.

A figura 3 apresenta, na forma de gráfico, as relações das quatro categorias de contextualização e instrumento elaborado para análise das nove unidades didáticas. 


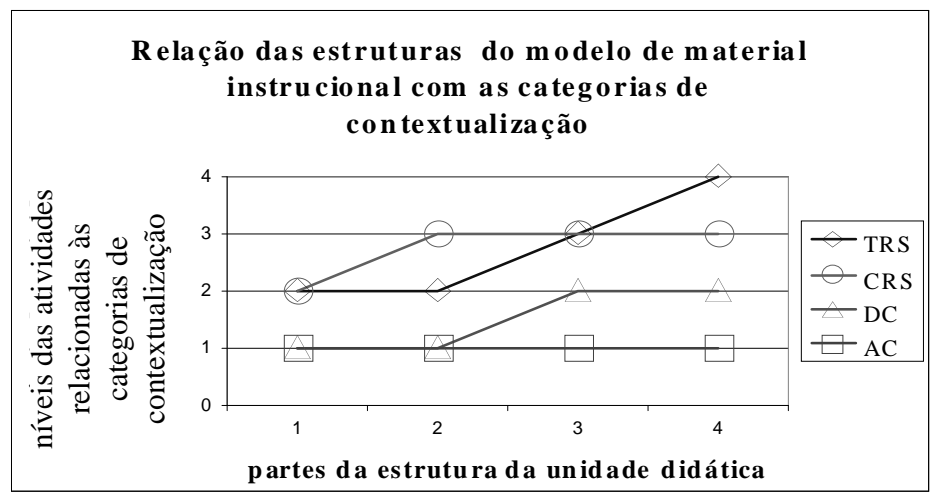

Figura 3 - Relação das estruturas do modelo de material instrucional com as categorias de contextualização

A partir dos perfis teóricos, pode-se realizar as aproximações da perspectiva de contextualização das unidades didáticas de seus respectivos autores com os modelos elaborados. A figura 4 apresenta as relações estabelecidas entre o perfil teórico de contextualização $\mathrm{AC}$ e as unidades didáticas 1(PG e PF) e 9(PN e PP):

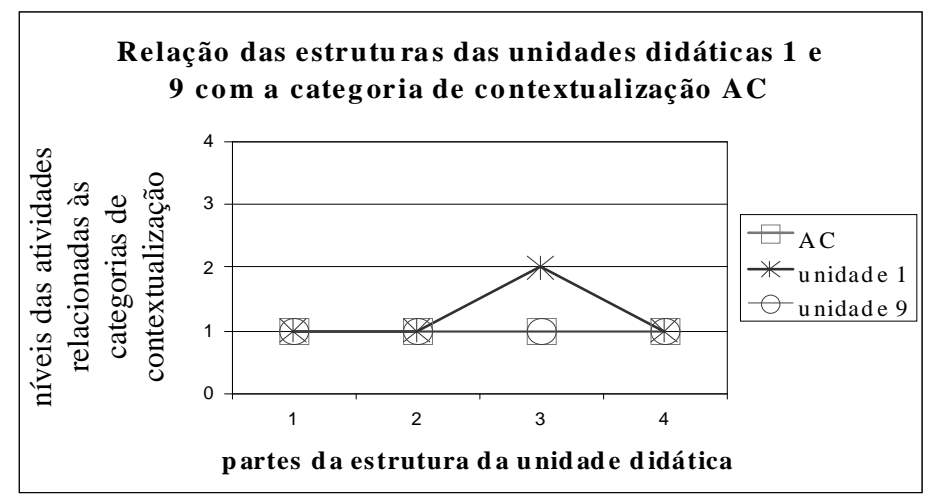

Figura 4 - Relação das estruturas das unidades didáticas 1 e 9 com as categorias de contextualização

As relações a partir das unidades 1 e 9, se aproximaram da categoria de contextualização AC, como podemos verificar na figura 4. Embora a unidade didática 1 apresente um nível mais elevado no que diz respeito aos conhecimentos da química, ou seja, relação média entre conteúdos da química e o tema, as duas apresentam características da referida categoria. Podemos afirmar, então, que as duas unidades didáticas apresentam maior correlação com a perspectiva de contextualização Aplicação de Conhecimento Químico.

Para a categoria DC, têm-se as unidades 3 (PE), 5(PL) e 8(PC e PQ) que apresentaram temas ao invés de situações problemas (estrutura 1 nível 1). A figura 5 apresenta as correlações dessas unidades com a categoria. 


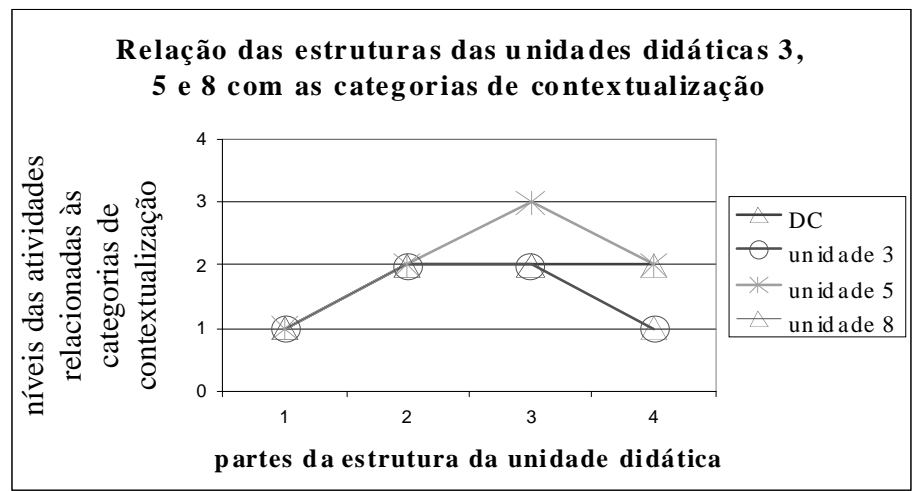

Figura 5 - Relação das estruturas das unidades didáticas 3, 5 e 8 com as categorias de contextualização

As unidades didáticas apresentam coincidências de pontos com os perfis da categoria DC, ou seja, as três unidades adotam temas geradores e apresentam os focos bem definidos na ciência. A unidade 5, porém, apresenta forte relação entre os conhecimentos químicos e o tema de trabalho. Todavia ao final, a unidade volta ao nível da categoria em questão, que é a retomada do tema sem maiores explicações. Já as unidades 3 e 8, apresentam os mesmos níveis estruturais entre si, porém em relação à categoria DC elas não alcançam o nível 2 (retomada do tema), ou seja, não apresentam uma nova visão do problema. Assim, as unidades 3, 5 e 8 apresentam características da categoria descrição de conhecimentos científicos.

Ainda na categoria DC, apresentam-se as unidades didáticas 4(PO) e 6(PA, PD e PI), embora estes materiais tenham apresentado uma situação problema (nível 2 da parte 1 da estrutura).

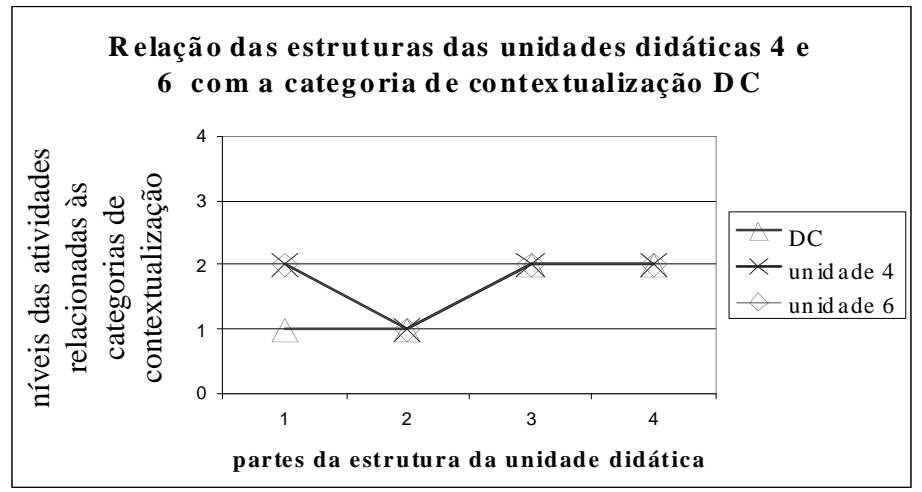

Figura 6 - Relação das estruturas das unidades didáticas 4 e 6 com a categoria de contextualização DC

Nas unidades 4 e 6, percebemos certa tendência C>TSA, ou seja, o nível 1 da parte 2 (Tema ou situação problema). Verificamos também que as duas unidades apresentam relação média entre os conteúdos químicos e a 
situação problematizada. Ao final, na estrutura 4 (Nova visão do tema ou problema), as unidades retomam a discussão da situação problema. Então, as duas unidades didáticas partem de um nível mais elaborado, porém, logo após, se nivelam aos níveis da categoria DC, o que as caracteriza nesta categoria.

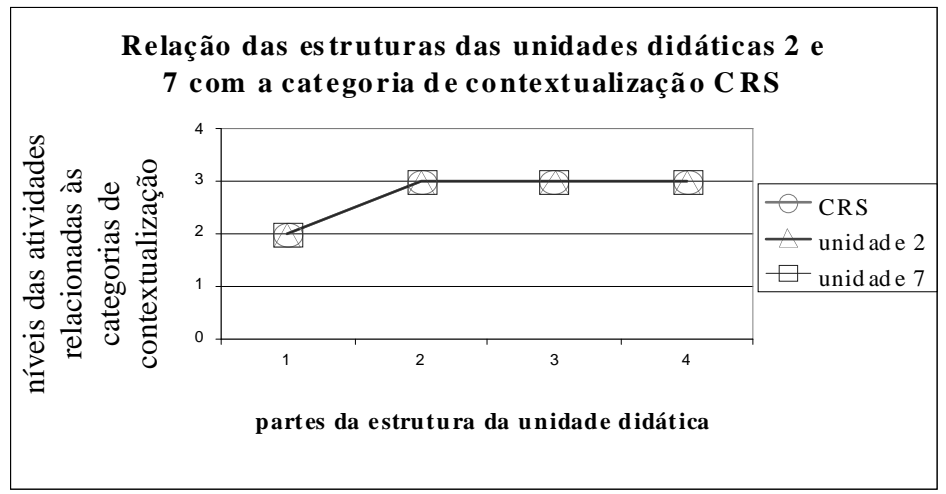

Figura 7 - Relação das estruturas das unidades didáticas 2 e 7 com a categoria de contextualização CRS

As unidades 2(PH) e 7(PB e PR), conforme aponta a figura 7, aproximam-se do modelo de contextualização CRS, compreensão da realidade social. Elas partem de um tema problematizado (nível 2, estrutura 1) e apresentam o nível $C=T S A$. Os conteúdos de química (estrutura 3), são tratados estabelecendo relações fortes com a situação problema. $\mathrm{Na}$ última parte da estrutura, a nova leitura da situação, as duas unidades apresentaram atividades que buscam promover julgamento e posicionamento frente a situações problemas, o que as colocam muito próximas da categoria CRS.

Considerando a categoria de contextualização TRS, transformação da realidade social, nenhuma unidade didática apresentou similaridades a ela, ou seja, em nenhuma das unidades foi verificado qualquer atividade de natureza de intervenção na realidade social, o que ajudaria a caracterizar a unidade nesta última categoria de contextualização. 
Tabela 3 - Ideias iniciais e perspectiva de contextualização das unidades didáticas dos professores

Ideias iniciais e perspectiva de contextualização das unidades didáticas de professores

\begin{tabular}{c|c|c|c}
\hline \multicolumn{2}{c}{ Professores } & $\begin{array}{c}\text { Entendimentos } \\
\text { no início dos encontros }\end{array}$ & $\begin{array}{c}\text { Perspectiva refletida na construção } \\
\text { das unidades didáticas }\end{array}$ \\
\hline 1 & PA & DC & DC \\
2 & PB & DC & CRS \\
3 & PC & DC & DC \\
4 & PD & DC & DC \\
5 & PE & AC & AC \\
6 & PF & AC & AC \\
7 & PG & DC \\
8 & PH & DC & DC \\
9 & PI & DC & Não entregou a unidade \\
10 & PJ & DC \\
11 & PL & CRS & não entregou a unidade \\
12 & PM & DC & AC \\
13 & PN & AC & DC \\
14 & PO & DC & AC \\
15 & PP & DC & AC \\
16 & PO & AC & CRS \\
17 & PR & & \\
\hline
\end{tabular}

A partir da tabela 3, que apresenta a relação entre os entendimentos iniciais e perspectivas de contextualização das unidades didáticas dos professores, pode-se apontar pelo menos quatro situações em relação à evolução dos professores: aqueles que parecem ter ampliado o entendimento de contextualização no ensino e trabalharam esses elementos de ampliação na construção de suas unidades didáticas (PH, PB e PR); os professores que não construíram suas unidades didáticas de acordo com o nível de entendimento que aparentemente foi ampliado no decorrer do curso (PA, PD, PI, PO e PQ); aqueles que parecem não ter ampliado seus entendimentos de contextualização tendo suas unidades didáticas características das categorias AC e DC, embora a categoria DC possa ser caracterizada num nível mais elevado que AC (PC, PE, PF, PG, PN, PL e PP) e os professores que participaram de todas as etapas do curso, porém não concluíram suas unidades (PM e PJ).

\section{CONCLUSÕES}

Neste trabalho foram utilizadas três perspectivas de contextualização: (i) exemplificação, ou entendimento, ou informação do cotidiano, (ii) entendimento crítico de questões científicas e tecnológicas relevantes que afetam a sociedade - característica do movimento CTS e (iii) transformação da realidade social - caracterizada pela inserção da prática social no ensino com vistas à transformação social.

Com relação aos resultados desta pesquisa, a maioria dos professores, caracterizou, inicialmente, a contextualização no ensino de Química como sim- 
ples exemplificação de fatos ou situações do cotidiano e poucos professores a entendiam como um recurso para realizar descrições científicas de fatos e processos. Entretanto, o estudo e reflexões sobre concepções de contextualização e análise de materiais didáticos parecem ter contribuído para certa ampliação das suas visões.

A investigação revelou que um grupo de professores (09) passou a reconhecer as diferentes perspectivas com que o ensino pode ser socialmente contextualizado, e outro grupo, oito (08) professores, não demonstrou compreensão das ideias de contextualização CTS e da transformação social.

Contudo, a construção por parte dos professores de seus materiais instrucionais (VIEIRA; VIEIRA, 2006; MAZZEU, 1998) foi uma ferramenta importante, tanto no aspecto da formação continuada, quanto da pesquisa. Esta estratégia possibilitou maior aproximação do cotidiano escolar do professor com os fundamentos estudados e julgados importantes no curso, possibilitando também aos pesquisadores investigar as ideias dos professores refletidas nesses materiais.

A análise das unidades didáticas desvelou um pequeno número de professores que mostraram ter ampliado seu entendimento de contextualização e construíram materiais em que esses elementos puderam ser reconhecidos; outros professores que pareciam ter ampliado seus entendimentos, não os refletiram na construção de suas unidades didáticas e finalmente, uma pequena parte dos professores que não manifestaram ter ampliado seus entendimentos de contextualização o que se refletiu na construção das suas unidades didáticas.

Essa pesquisa aponta a necessidade de outros estudos que tragam mais contribuições para entender os mecanismos de barreiras epistemológicas, afetivas, cognitivas, que controlam escolhas e decisões dos professores no processo educativo e, de certo modo, os impedem de colocar em prática todo seu potencial compreensivo a respeito de um ensino contextualizado. Assim, é necessária a formação de grupos de professores que investiguem suas próprias práticas e possam, numa ação mediada, aprofundar seus conhecimentos e as reflexões sobre o significado e importância da educação científica e tecnológica para todos (CARVALHO; GIL-PÉREZ, 1998).

\section{NOTAS}

${ }^{1}$ As Diretorias de Regionais de Ensino são órgãos constitutivos da Secretaria de Estado da Educação do Estado de São Paulo, responsáveis pela gestão de um determinado grupo de escolas.

${ }^{2}$ Pitombo et al. (coord.) Projeto Pró-Ciências. São Paulo: Fapesp, 2001.

${ }^{3}$ Foram utilizados códigos para representar cada um dos professores, a fim de preservar suas identidades. 


\section{REFERÊNCIAS BIBLIOGRÁFICAS}

ACEVEDO, J. A. Cambiando la práctica docente en la enseñanza de las ciencias através de CTS. Revista Borrador, v.13, 1996. Disponível em:

<http://www.campus-oei.org/salactsi/acevedo2.htm>. Acesso em: 04 abril 2006.

ACEVEDO, J. A.; VÁZQUEZ, A.; MANASSERO M. A. Papel de la educación CTS en una alfabetización científica y tecnológica para todas las personas. Revista Electrónica de Enseñanza de las Ciencias, v. 2, n. 2, 2003. Disponível em: <http://www.saum.uvigo.es/reec/volumenes/volumen2/> Acesso em 20 Mar. 2006.

AIKENHEAD, G. S. The social contract of science: implications for teaching science. In: SOLOMON, J. e AIKENHEAD, G. (Eds.), STS education - International perspectives on reform. New York: Teachers College Press, 1994.

AULER, D. Alfabetização Científico-Tecnológica para quê? Ensaio - Pesquisa em Educaşão em Ciências, Belo Horizonte, v. 3, n. 2, 2001.

Alfabetização Cientifico-Tecnológica: um novo "Paradigma"? Ensaio - Pesquisa em Educaşão em Ciências, Belo Horizonte, v. 5, n. 1, 2003.

AULER, D.; FENALTI, V. S.; DALMOLIN, A. M. T. Abordagem temática: temas em Freire e no enfoque CTS. In: Encontro Nacional de Pesquisa em Ensino de Ciências, 6, 2007, Florianóplis. Anais... ABRAPEC - Associação Brasileira de Pesquisa e Educação em Ciência, 2007. Disponível em: <http://www.fae.ufmg.br/abrapec/cdrom/entrar.htmlhttp://www.saum.uvigo.es/reec/volumen es/ volumen2/> Acesso em 23 jun. 2008.

BRASIL. Secretaria de Educação Média e Tecnológica - Ministério da Educação e Cultura. Parâmetros Curriculares Nacionais do Ensino Médio. Brasília: MEC/SEMTEC, 1999.

BRASIL. Secretaria de Educação Média e Tecnológica - Ministério da Educação e Cultura. PCN + Ensino Médio: Orientações educacionais complementares aos Parâmetros Curriculares Nacionais. Brasília: MEC/SEMTEC, 2002.

CAJAS, F. La alfabetización científica y tecnológica: la transposición didática del conocimiento tecnológico. Enseñanza de las Ciencias, v. 19, n. 2, 2001.

CARVALHO, A. M. P.; GIL-PÉREZ, D. Formação de professores de ciências: tendências e inovações. São Paulo: Cortez, 1998. (Coleção Questões da Nossa Época).

CHASSOT, A. Alfabetização Cientifica: questões e desafios para a educação. 2.ed. Ijuí: Unijuí, 2001. (Coleção Educação em Química).

DELIZOICOV, D.; ANGOTTI, J. A. Física: formação geral. São Paulo: Cortez, 1991. (Coleção Magistério).

DELIZOICOV, D.; ANGOTTI, J. A e PERNAMBUCO, M. M. Ensino de Ciências: fundamentos e métodos. São Paulo: Cortez, 2002.

FREIRE, P. Ação cultural para a liberdade e outros escritos. 10.ed. Rio de Janeiro: Paz e Terra, 2002.

LUTFI, M. Os Ferrados e Cromados: produção social e apropriação privada do conhecimento químico. Ijuí: UNIJUÍ: 1992.

MACHADO, N. J. Educação: projetos e valores. 5 ed. São Paulo: Escrituras: 2004. (Coleção Ensaios Transversais).

MAZZEU, F. J. C. Uma proposta metodológica para a formação continuada de professores na perspectiva histórico-social. Cad. CEDES, Campinas, v. 19, n. 44, 1998. Disponível em:

$<$ http: / / www.scielo.br/scielo.php?script=sci_arttext\&pid=S010132621998000100006\&lng=pt\&nrm=iso >. Acesso em: 23 fev. 2007.

PIMENTA, S. G. Professor reflexivo: construindo uma crítica. In.: PIMENTA, S. G. GHEDIN, E. (Orgs.) Professor Reflexivo no Brasil: gênese e crítica de um conceito. 2 ed. São Paulo: Cortez, 2002. PIMENTA, A. G.; GARRIDO E.; MOURA, M. O. A Pesquisa Colaborativa na Escola como Abordagem Facilitadora para o Desenvolvimento da Profissão do Professor. In: MARIN A. J. (Org.). Educaşão Continuada: reflexões, alternativas. 2 ed. São Paulo: Papirus, 2004.

SANTOS, W. L. P.; MORTIMER, E. F. Concepções de Professores sobre Contextualização Social do Ensino de Química e Ciências. In: Reunião Anual da Sociedade Brasileira de Química, 22., 1999, Poços de Caldas, MG. Livro de resumos. São Paulo: Sociedade Brasileira de Química, 1999. 
SANTOS, W. L. P. Uma análise de pressupostos teóricos da abordagem C-T-S (Ciência Tecnologia - Sociedade) no contexto da educação brasileira. Ensaio - Pesquisa em Educação em Ciências, v. 2, n. 2, 2002.

SÃO PAULO. Secretaria da E. Coordenadoria de Estudos e Normas Pedagógicas. Oficinas temáticas no ensino público visando à formação continuada de professores. São Paulo: Imprensa Oficial do Estado de São Paulo, 2007.

TEIXEIRA, P. M. M. A Educação cientifica sob a Perspectiva da Pedagogia Histórico-critica e do movimento CTS no ensino de ciências. Ciência \& Educação, Bauru. v. 9, n. 2, 2003.

VIEIRA, C. T. VIEIRA, R. M. Construção de práticas didático-pedagógicas com orientação CTS: impacto de um programa de formação continuada de professores de ciências do ensino básico. Ciência e Educação, v. 11, n. 2, 2005.

WARTHA, E. J. O ensino médio numa dimensão político-pedagógica: os parâmetros curriculares nacionais, o ensino de química e o livro didático. 2002. 145p. Dissertação (Mestrado em Ensino de Ciências) - Programa Interunidades IF, IQ, IB e FE, Universidade de São Paulo, São Paulo. 
